\title{
The State Unified Exam as a Requirement in Russia's New Economic Relations
}

\author{
Arsen A. Tatuev ${ }^{1}$, Dmitriy A. Edelev ${ }^{1} \&$ Anzor H. Zhankaziev ${ }^{1}$ \\ ${ }^{1}$ Moscow State University of Food Production, Moscow, Russian Federtation \\ Correspondence: Arsen A. Tatuev, Moscow State University of Food Production, 125080, Moscow, \\ Volokolamskoye, 11, Russian Federation.
}

\author{
Received: October 14, 2014 Accepted: November 23, 2014 Online Published: February 25, 2015 \\ doi:10.5539/ass.v11n6p176 URL: http://dx.doi.org/10.5539/ass.v11n6p176
}

\begin{abstract}
This article examines the issues of the low quality of knowledge, reflected in the results of the last State Unified Exam (SUE), in the context of the shift of the national economy of the Russian Federation towards innovative national development. A special focus is on the analysis of recent years' changes in SUE results and the low effectiveness of the use of relevant resources in the educational system. The author proposes integrating the principle of continuing individualized education with the financial capabilities of the state and the population through the use of the mechanism of a universal electronic card.
\end{abstract}

Keywords: knowledge economy, State Unified exam, higher education reform, educational services, universal electronic card

\section{Introduction}

The State Unified Exam remains one of the most challenging subjects in terms of Russian education reform. The recent 12-point decrease in the threshold SUE minimum in Russian sparked a wave of both criticism and support on the part of the public.

However, we should approach the exam results with care not just in terms of the present-day state of Russian education but rather in terms of prospects in the development of society itself (Gorin et al., 2013; Trukhachev, 2013; Zaitseva \& Popova, 2013). It is the latter, in our view, that there is a lack of.

When it comes to arguments behind the criticism, the most common ones suggest that the current system of knowledge control is destroying its content and the very secondary school, whose graduates are keen on not so much acquiring knowledge but being able to pass tests, rather. Many colleges are unable to enroll the right students, with the list of those instituting additional entrance trials increasingly growing.

Reform proponents, those in favor of reforming the SUE in particular, are talking about easing entering the capital's colleges for children from remote regions.

But the question arises as to what particular facts have to do with future social-economic development, whether the development of education in Russia is oriented towards improving the quality of selection of future students or whether education has to fulfill major social-economic functions, and where the issue of selection fits here then, in the first place.

It should be noted, above all, that amid the transformation of modern society into a knowledge society the educational system is becoming a central organizational-economic instrument for the formation of a new quality of human capital (Bobryshev et al., 2014; Gerasimov et al., 2014). Furthermore, educational services themselves have turned into an object for the formation of new economic and financial relations, which will be the basis of the entire social-economic system.

In this context, all employed instruments for reforming education ought to be oriented not towards enhancing and developing existing economic relations (Trukhachev et al., 2014; Gerasimov et al., 2013; Berezhnoy et al., 2014) but be adapted to the relations of the knowledge economy.

At the same time, the major objectives in the development of the educational system, established for the near future, do not address the most crucial point-raising the issue of the making of a new system of funding education, the 
hour for which is intrinsically ripe right now and which is crucial to the shift to a knowledge society (Sklyarov \& Sklyarova, 2009).

\section{Methods}

An increase in the share of science-intensive production, inherent to the knowledge economy, provides a rationale for increased demand for a highly qualified workforce. In a market economy, people who are more educated have the opportunity to receive a higher remuneration for their work. Furthermore, human capital accumulated as a result of going to college translates into not just economic benefits but an improvement in the quality of life.

A top priority for state policy makers in the sphere of education is boosting the quality and level of education for all strata of the population regardless of the citizen's descent, income, and place of residence. Over recent years, the overall number of those attending educational institutions of all levels has been an average of 29 million per year, i.e. over $20 \%$ of the population of the Russian Federation. The overall number of those attending institutions of preschool and general learning is about 19 million people, while the number of students going to institutions of professional learning is about 10 million people (Saprankov, 2013).

Over $70 \%$ of the total volume of funding from the federal budget is directed into the sphere of higher education. Furthermore, all allocated funds are aimed at boosting the quality of education and preparation of specialists and human resources whose competence will fully meet the requirements of the present-day labor market.

Higher education governs the immediate increase in the economic and social effectiveness of individuals. Thus, education acts as an investment sector and a source of growth in human capital, which is something other areas of activity cannot accomplish (Toffler, 2002; Coombs, 1985). The aim of the modern educational system is to develop the overall cultural level, ensure the acquisition of fundamental knowledge, and foster the ability to study and develop personal competencies, on the basis whereof practical skills are formed.

The operation of the modern educational system is aimed at boosting the overall cultural level of man, the acquisition of knowledge by him, as well as the formation of practical skills in him. These days, employers are setting quite high requirements on the level of training of specialists, demanding from them a broad spectrum of both professional and personal competencies. The formation of a highly-educated individual is grounded in the development of the following competencies:

- social, which deal with the individual's ability to make responsible decisions, work in a team, and resolve conflict situations;

- intercultural, which are about respecting others as well as the ability to interact effectively with representatives of other cultures, languages, and religions;

- communicative, which deal with having a competent command of speech and more than one language;

- information, which are about the ability to apply information-communications technology;

- the capacity for continuing education.

The above competencies serve as instruments for the accumulation and development of human capital.

Investing in human capital is closely linked with issues in the operation of the market of educational services, which play a central role in the process of formation of a qualified workforce and reflect the investment character of expenditure on education on the part of students. Education in Russia remained free for students for a long period of time. Today the opportunity to study on a paid basis is provided by both commercial and state-run colleges. Investing money in education, the individual thereby takes an active part in the formation of human capital.

Besides, over the last decade we have seen a substantial increase in the number of students attending universities, institutes, and academies in Russia. Note that according to the annual overview of major OECD indicators in the sphere of education, Canada, Korea, and the Russian Federation are leading the OECD member states and the G-20 on the share of young people (25-34 years of age) with a higher education.

By facilitating the build-up of human capital, the developed market of educational services makes a tangible impact on the labor market. A key issue in present-day higher education is the mismatch between curricula and the needs of business. Enterprises are often in need of additional training for their personnel, in terms of not just issues related to a specific narrowly professional sphere but in terms of basic education, as well as relevant qualifications. In this regard, an objective of educational institutions becomes forecasting trends in the development of the labor market and adapting curricula in accordance with those trends. 


\section{Results}

A great impact on the development of innovation activity in the system of higher education has been made by the implementation of innovation programs as part of a priority national project entitled "Education". As a consequence, through budget funds a substantial number of colleges managed to substantially augment the innovation component, which deals with developing and commercializing scientific-technical achievements.

With the implementation of the project, colleges that won received an opportunity to use additional funding and the engaged funds depending on the potential they already had as well as their field of activity. Technical and classic universities directed the major volume of funds at upgrading the instrument base of science and education, and colleges specializing in humanities and social sciences at developing new learning methodologies and training human resources, including those for innovation entrepreneurship.

The implementation of educational programs helped augment the crucial elements of colleges' innovation infrastructure, such as student business incubators, technology transfer centers, and academic-scientific-innovation complexes. The specificity of the latter lies in a combination of scientific, educational, and production resources, which in the future facilitates ensuring a new quality of education, the development of scientific research, and commercialization of the results of scientific-technical activity.

Furthermore, one of the more known mechanisms for assessing the quality of education in Russia is the State Unified Exam (SUE). The SUE is an examination conducted in a centralized fashion in secondary educational institutions based on secondary general education curricula. It serves simultaneously as a final examination and an entrance examination to enter a college. The application of the SUE throughout the country involves using single-type assignments and grading methods.

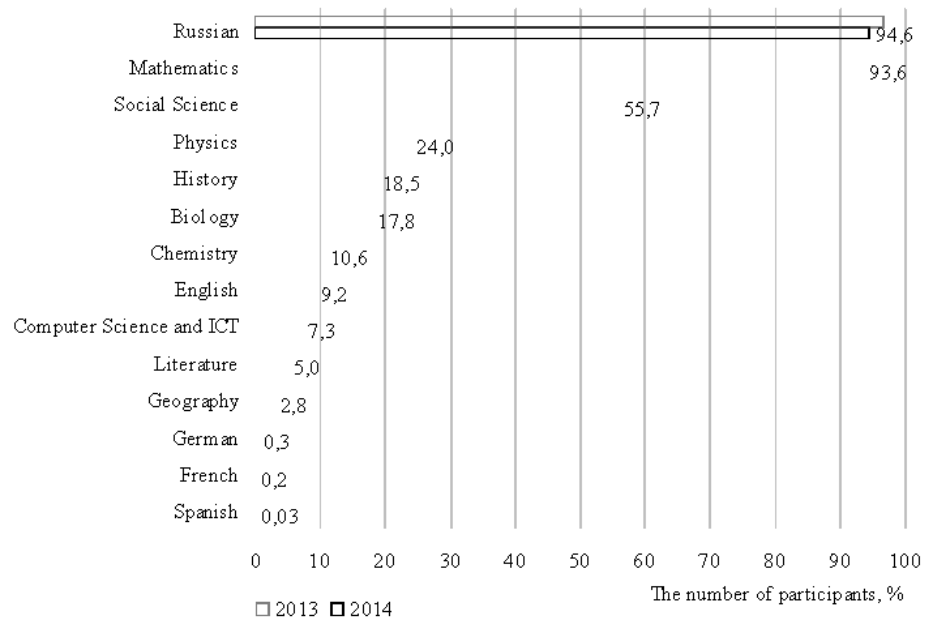

Figure 1. The distribution of the total number of SUE participants across subjects, $\%$

In 2014, the SUE was taken by about 757 thousand people. Out of those, $94.6 \%$ were graduates in that year. The rest, 5.4\%, were retaking the exam. To compare, in 2013 graduates in that year accounted for $86.1 \%$. Note that, on the whole, the number of SUE participants was greater- 863 thousand people. Figure 1 provides a diagram illustrating the distribution of the overall number of SUE participants across subjects over 2013-2014. The diagram indicates that virtually all participants took Russian and Mathematics, which are compulsory subjects needed to be taken to receive a diploma. The rest of the subjects were sat for on a voluntary basis, in any number, in accordance with which specialty (training field) the student was planning on receiving a professional education in. Among voluntary subjects, the majority of the participants-over a half-were sitting for Social Science. A much lower number of graduates picked Physics, History, and Biology. And an even lower number picked English, Computer Science, Literature, and Geography. Very few sat for German, French, and Spanish. Note that the structure of distribution of subject preferences among participants in 2014 did not change much relative to 2013. Out of 757 thousand participants in 2014, the SUE was failed by 5 thousand students $(0.7 \%)$, and in 2013 out of 863 thousand it was failed by 6.5 thousand $(0.8 \%)$.

Despite all the advantages, right from the moment the SUE was introduced, as an experiment first and a fully instituted exam later on, it became a subject of heated debate. The major issues of debate were the objectiveness of grading students' knowledge and result rigging. The first issue involved the argument that based on the SUE 
methodology the likelihood of a well-prepared graduate getting a high score was higher than that of he/she getting a low score. By the same token, there was talk of the likelihood of poorly prepared graduates getting low scores (Shakhariyants, 2010). Regarding the second issue, the holding of the SUE has been accompanied by a slew of headline-making cases over all of the last years. Thus, in July, 2013, a major leak of monitoring/measuring materials (MMM) triggered the dismissal of the Deputy Minister of Education and Science of the Russian Federation, who supervised the SUE (Fursenko, 2013). However, 2014 proved exceptional in that respect. No cases of a leak of MMMs prior to the exam were recorded. Besides, the fair holding of the exam locally was ensured through unprecedented control measures-the examination classrooms had been equipped with metal detectors and surveillance cameras.

Tougher control measures led, on the one hand, to a substantial increase in expenditure on organizing the SUE. Thus, in 2013 it cost 500 million rubles. In 2014, the SUE was funded on all respects at the level of the previous year. Besides, additional funds were expended on installing video-cameras (600 million rubles) and implementing tougher control measures regarding the delivery of monitoring/measuring materials to some regions (63 million rubles). Note that the additional activities cost the budget more than all the major expenses.

\section{Discussion}

In an information society, science becomes a sort of generator of human capital. The scientific-technical component of human capital, thus, becomes one of the top national priorities. The development of human capital, the technological modernization of production, and the shift to the innovative path of economic development are the basis for future economic growth and a real alternative to the country's raw-materials specialization.

The country's modernization potential directly depends on a consistent shift to innovative economic development (Tatuev, 2013). An important factor in this shift is the formation, development, and accumulation of human capital. The interaction of development processes could be pictured as a helix (education-human capital-innovative economy-education). Education ensures the accumulation of human capital; a high level of human capital governs the successful flow of innovation processes within the economy, which, in turn, determines the implementation of new technology in the educational process and facilitates the development of human capital, etc. This helix reflects the onward progress of the innovative knowledge economy.

Science and higher education ought to be in line with the needs of modern society and emerging trends in its development. Currently, the adaptation capabilities of the educational system are lagging behind the pace of economic transformations-primarily, in terms of the dynamics of demand for specialists. Knowledge acquired in educational institutions does not match knowledge required of specialists in the labor market. There are various ways to overcome this gap: through internships, career enhancement, getting additional education, retraining, self-education, etc. In present-day conditions, all of the above ways ought to be put into practice on a constant basis, i.e. in the continuing education mode. However, all of them require substantial expenses, including financial expenditure.

Today we can assert that the human potential of Russia's scientific-technical and educational sphere is being reproduced quite inefficiently, which, among other reasons, is due to a lack of young human resources. In large part, this is associated with a number of material reasons-low salaries, trouble resolving housing issues, outmoded jobs and equipment. Besides, many researchers are noting changes in the cultural status of science in Russia-once a supreme value, science is now getting transformed into quite an ordinary, value-wise, social and cultural phenomenon.

The Concept of the Long-Term Social-Economic Development of the Russian Federation through to 2020 sets out the major dimensions of the shift to the innovative, socially-oriented path of national economic development. The Concept-2020 states that shifting Russia's economy to the innovative path of development will require forming a globally competitive national innovation system and a complex of legal, financial, and social institutes, which would ensure the interaction of educational, scientific, entrepreneurial, and non-commercial organizations and establishments in all spheres of the economy and social life (Gerasimov et al., 2013). The formation of a national innovation system capable of ensuring the effective integration of higher education and science can ensure the shift from the export/raw materials model to the innovation model for economic growth.

According to the Concept, a crucial characteristic of the shift to the innovative, socially-oriented path of national economic development is the need for the simultaneous resolving of the objectives of both catch-up and advanced development. The conditions of global competitiveness and open economy make it impossible for the Russian economy to reach the level of developed countries on indicators of welfare and efficiency, which cannot be achieved without ensuring the advanced development of those sectors of the Russian economy which determine its 
specialization within the global economic system and ensure the most effective realization of national competitive advantages.

Among the issues with the existing model for economic growth is the increase in the population's income, which is outstripping the pace of growth in the GDP, which, in turn, is accompanied by the augmentation of economic differentiation.

Consequently, the shift from the export/raw materials model to the innovation model for economic growth ought to be based on the formation of a new mechanism for social development, which should be predicated on a balance between entrepreneurial freedom, social justice, and national competitiveness. Regarding the development of Russia's human potential, the Concept speaks of the need for a shift from the system of mass education, typical of industrial economies, to the system of continuing, individualized education for all, which is crucial to creating an innovative socially-oriented economy, the need for the development of a type of education that will be indissolubly linked with global fundamental science and oriented towards the formation of creative, socially responsible personality.

However, the development of innovation activity in the system of higher education is impeded by a set of internal and external factors (Tatuev, 2012). The internal factors are:

- the low innovation activity of instructors, as well as a lack of specialists in the area of innovation management;

- the outmoded material-technical base of colleges, outmoded testing and experimental operations, and, as a consequence, the absence of a full cycle of innovative product creation;

- the low development level of college infrastructure;

- poor cooperation between universities, as well as between universities and regions' industrial, economic, and social spheres.

The external factors for the low innovation activity in the sphere of education are:

- the lack of mechanisms for active government support of small innovative enterprises under colleges;

- the ineffectiveness of government support of innovation infrastructure facilities.

Table 1. The dynamics of change in the average SUE test scores in the subjects over the period from 2013 to 2014

\begin{tabular}{llll}
\hline Subject & 2013 & 2014 & Index of gain in results. \% \\
\hline Spanish & 69.3 & 72.3 & 4.3 \\
French & 69.8 & 69.9 & 0.1 \\
Russian & 63.9 & 62.5 & -2.3 \\
German & 59.7 & 55.1 & -7.6 \\
Geography & 57.6 & 53.1 & -7.7 \\
Biology & 59.1 & 54.3 & -8.1 \\
Literature & 59.9 & 54.1 & -9.8 \\
Computer Science and ICT & 63.5 & 57.2 & -9.9 \\
Social Science & 60.1 & 53.1 & -11.7 \\
English & 73.0 & 61.3 & -16.1 \\
Physics & 54.6 & 45.8 & -16.3 \\
History & 55.9 & 45.7 & -18.2 \\
Chemistry & 68.7 & 55.7 & -18.9 \\
Mathematics & 49.6 & 39.6 & -20.1 \\
\hline
\end{tabular}

Here we get to the most complicated issue-towards what and how to orient the system of management of higher education. First and foremost, we need to resolve the existing contradiction whereby, on the one hand, higher education has become a key factor in the development of human capital, while, on the other, the system of management of its development is increasingly oriented towards redistribution relations-which has been demonstrated by the results of the last SUE.

It is in this context that we may find interesting other results of having made control measures tougher-a substantial decrease in scores. Table 1 provides information that lets us assess the dynamics of change in the average SUE test 
score in the subjects over the period from 2013 to 2014. The table provides values for average test scores recorded in 2013 and 2014 and contains an index of gain in results (obtained through dividing the difference between the 2014 value and the 2013 value by the 2013 value and multiplying the result by 100 ), which is expressed in \%.

We can see from the table that the average score has increased only in Spanish and French. However, considering the low number of SUE participants who sat for those subjects, those values are not representative. The most representative is the situation with Mathematics, where the average score has dropped from 49.6 to $39.6-\mathrm{a} 20.1 \%$ decline. There is an $11.7 \%$ decline in Social Science-the average score has fallen from 60.1 to 53.1. There have also been quite negative changes in the results in Physics, History, and Biology. In Physics, the average score has dropped from 54.6 to 45.8 -a $16.3 \%$ decline. In History, the average score has fallen from 55.9 to 45.7 -an $18.2 \%$ decline. In Chemistry, the average score has dropped from 68.7 to 55.7 -an $18.9 \%$ decline.

Table 2. The dynamics of change in the number of SUE participants who scored 100 points in the subjects over the period from 2013 to 2014

\begin{tabular}{llll}
\hline Subject & 2013 & 2014 & Index of gain in results, \% \\
\hline Russian & 0.31 & 0.33 & 9.3 \\
Literature & 1.03 & 0.56 & -45.8 \\
French & 0.32 & 0.15 & -53.9 \\
Physics & 0.23 & 0.08 & -65.0 \\
Geography & 0.93 & 0.27 & -71.1 \\
Biology & 0.29 & 0.08 & -72.3 \\
History & 0.30 & 0.07 & -76.8 \\
Chemistry & 3.43 & 0.60 & -82.6 \\
Social Science & 0.10 & 0.02 & -85.4 \\
Mathematics & 0.07 & 0.01 & -86.5 \\
Computer Science and ICT & 0.95 & 0.06 & -93.2 \\
English & 0.78 & 0.02 & -98.0 \\
German & 0.14 & 0.00 & -100.0 \\
Spanish & 0.00 & 0.00 & - \\
\hline
\end{tabular}

Against the backdrop of the declining average score, we observe a rather negative dynamics with the situation involving a decrease in the number of 100-pointers-SUE participants who scored 100 points on the exam in a subject. Table 2 provides information that lets us assess the dynamics of change in the number of SUE participants who scored 100 points in the subjects over the period from 2013 to 2014. The table provides values for the shares of participants who scored 100 points in the subjects over 2013 and 2014 and an index of gain in results (obtained through dividing the difference between the 2014 value and the 2013 value by the 2013 value and multiplying the result by 100), which is expressed in \%.

The table shows that in some subjects there are no longer any 100-pointers whatsoever (German), while in other subjects the number of such participants has declined considerably. Thus, for instance, in Mathematics there is a drop from 0.07 to $0.01 \%$-an $86.5 \%$ decline. In Social Science, the decline is $85.4 \%$ (from 0.1 to $0.02 \%$ ), in Physics $65.0 \%$ (from 0.23 to $0.08 \%$ ), in History- $76.8 \%$ (from 0.3 to $0.07 \%$ ), and in Chemistry- $82.6 \%$ (from 3.43 to $0.6 \%$ ). The only improvement here has been recorded just in Russian, a $9.3 \%$ gain-from 0.31 to $0.33 \%$ of the 100 -pointers. The total number of participants who scored 100 points has dropped from 9 to 3.5 thousand.

In the meantime, even the above dynamics does not reflect the entire picture, since the overall decline in SUE results has been counterbalanced in an artificial way-by lowering the minimum number of points in the compulsory subjects-Russian (from 36 to 24 points) and Mathematics (from 24 to 20 points). It is this step that made it possible to smooth over the negative exam results-as a matter of fact, the same step led to making the unsatisfactory result stand. Thanks to this step, the number of those who failed to pass the assessment in the compulsory subjects and will not be able to receive a secondary general education diploma in 2014 has decreased, as has been stated above, to 5 thousand people. However, the real figures could have been a lot higher. Thus, according to some data, if the passing score had not been lowered, just the exam in Russian could have been failed this year by as many as 30000 graduates. According to other data, if it had not been for the reduction in the passing 
score in both subjects, as many as $20-25 \%$ of graduates could have failed to get a diploma-and that considering the fact that, on the whole, as many as $4 / 5$ of graduates, technically speaking, received $3 \mathrm{~s}$ or failed the assessment altogether (Burmatov, 2014).

Table 3. The differentiation of the population of different populated localities by the average SUE test score in the subjects in $2013, \%$

\begin{tabular}{llll}
\hline & \multicolumn{2}{l}{ Type of populated locality } & Index of differentiation, \% \\
\hline Spanish & 39.0 & 69.3 & 77.6 \\
German & 44.1 & 60.7 & 37.7 \\
English & 57.9 & 73.7 & 27.3 \\
Computer Science and ICT & 52.3 & 64.8 & 24.1 \\
French & 57.3 & 70.0 & 22.0 \\
Physics & 50.2 & 54.4 & 8.2 \\
Russian & 59.8 & 64.5 & 7.9 \\
Geography & 54.6 & 58.3 & 6.7 \\
Social Science & 56.7 & 60.3 & 6.3 \\
Chemistry & 64.8 & 68.9 & 6.2 \\
Mathematics & 46.8 & 49.3 & 5.3 \\
Biology & 56.6 & 59.5 & 5.2 \\
Literature & 56.8 & 58.7 & 3.3 \\
History & 53.6 & 55.2 & 2.9 \\
Total & 54.4 & 58.5 & 7.5 \\
\hline
\end{tabular}

Besides, holding a fair SUE illustrated the scale of one other issue-differentiation in the quality of work by different schools. Table 3 provides information based on which we can assess the differentiation of the population of different types of populated localities by the average SUE test score in the subjects in 2013. More specifically, the table provides values for average SUE test scores in the subjects among SUE participants who attended rural and urban schools. Then, based on this data, the differentiation index was calculated (through dividing the difference between the average score achieved in the subject by participants from urban schools and that by participants from rural schools by that by participants from rural schools and multiplying the result by 100).

As we can see from the table, the average score in all the subjects taken together achieved by urban school graduates is $7.5 \%$ higher than that achieved by rural school graduates. Note that urban school graduates lead in all the subjects. That is, as a rule, urban schools prepare students for the SUE better. When it comes to the compulsory subjects, the differentiation is at the following levels: Mathematics-5.3\%; Russian-7.9\%. For Social Science it is $6.3 \%$. The highest is the level of differentiation in the foreign languages and Computer Science-from 22.0 to $77.6 \%$.

On the whole, the results of the SUE held in 2014 characterize most eloquently the fundamental issue faced by the national educational system-the low level of the quality of its performance. This fact has been confirmed by the Minister of Education and the President, as well as other competent persons, with modernization stated to await the educational system. That said, modernization will again be carried out through targeted, pinpoint measures. Thus, for instance, there are plans to reconsider academic programs related to teaching Russian and requirements on the quality of work of instructors. For that purpose, on the initiative of the Federal Service for Supervision of Education and Science there will be set up a task force to deal with issues related to enhancing teaching Russian, which will focus on improving teachers' level of qualification (Chernykh, 2014).

However, the efficiency of the activities proposed was immediately called into doubt (Kovalenko, 2014). More specifically, there is an argument whereby the across-the-board use of the SUE mechanism to assess the quality of education has led to the reorientation of secondary general education from the imperatives of preparing "worthy 
members of modern society" to the imperatives of "cramming students for tests" (Privalov, 2014). Besides, there is the issue of using the SUE to assess the quality of work done by governors and various executives in the system of education. Note that, in point of fact, the entire blame for someone's low grades has been put on the instructors, as a result of which there emerged talk of the latter's low level of qualification, the lack of young human resources, and the insufficient level of motivation.

The same year saw the abolition of the criterion of assessing governors based on SUE results. Besides, they instituted a ban on condemning instructors and schools whose students got the lowest exam scores (Privalov, 2014), since such approaches are deemed absolutely nonsensical, particularly considering the fact that the preparation level at the capital's high schools is much higher than that at rural schools. However, the measures planned, in company with the attempt to raise teacher salaries, are not likely to change things much, since they are not aimed at resolving fundamental errors laid down in the national educational system over the last years of reform. Most of the measures are aimed exclusively at improving the SUE mechanism, which, in essence, is a mechanism for control of the quality of the educational system. Even when we are talking about altering the programs, enhancing instructors' level of qualification, and engaging young specialists, it is still primarily about achieving the best results in the exam in the future. However, virtually no attention is given to problems faced by the educational system per se amidst the realities of a new society-a knowledge society wherein it is man and his knowledge that become the major element of production capital, his capacity for learning and applying his skills in practice. The results of the 2014 SUE have demonstrated that it is this issue that most graduates had serious trouble with. 4/5 of graduates (those who had $3 \mathrm{~s}$ or failed the attestation altogether) possess zero knowledge and have not been taught the skills of self-education. Therefore, the likelihood of graduates having learned anything major on leaving school is quite low. Consequently, this $4 / 5$ of graduates cannot already become the basis for the development of a knowledge society in Russia. In other words, $4 / 5$ of all resources expended on students in the educational system have virtually been wasted.

\section{Conclusion}

In our view, we should focus our high education management priorities on building a new system of economic and, principally, market relations encompassing both corporate and national levels. The object of these relations should be the formation of integrated and targeted investments in human capital in the form of specific funding of the system of higher education. Furthermore, it is expedient to form criteria for the effectiveness of this type of investment taking account of the immediate interests of the population as the major consumer of higher education services.

At the same time, these activities will not presuppose the immediate material interest of the very students and institutional establishments at all levels.

The technological vista of realizing the immediate priority of motivational factors is opening up at the modern stage of effectuating administrative reform, as part of which there was passed the Federal Law \# 210-FZ of July 27, 2010 "On Organizing the Provision of State and Municipal Services", which provides for the issuance of universal electronic cards for citizens.

Such a card will be a material carrier containing digital information on the owner and his/her rights to consume state and municipal services. Accordingly, such universal electronic cards can be used by RF citizens as well as foreign citizens when provided for by federal laws.

The universal electronic card will become an informative document that will serve as proof of a citizen's identity, the rights of an insured person in compulsory insurance systems, and other rights of a citizen to consume state and municipal services, including in the sphere of education. Thus, users of universal electronic cards become immediate participants in budget-administration relations. In this regard, it is important to work out principles that would make it possible to organize, through universal electronic cards, the administration of monies in budgets and non-budget funds at different administrative levels and direct them towards payment for educational services, including with the possibility of adding personal funds by citizens and corporations.

On this basis, there is being formed a new structure of economic relations associated with the provision of educational services. These relations will help to substantially increase the revenue of institutions of higher learning and form more equal conditions for access to quality higher education for people from all walks of life. In this context, there are additionally developed the motives of increase in personal expenditure on acquiring knowledge, which determine the primary specificity of corresponding systems of management and the trajectory of the development of higher school management. 


\section{References}

Berezhnoy, V. I., Berezhnaya, Y. V., Gerasimov, A. N., Gromov, Y. I., \& Shatalova, O. I. (2014). Systematic and Subsistential Analysis of the Conditions of Stable Development of Local Mono-Product Markets. Life Sci. J., 11(8), 596-599.

Bobryshev, A. N., Golchenko, Y. V., \& Kazakov. (2014). Directions of Municipal Territorial and Economic Transformation in a Monopolar Highly Urbanized Region. Aktualni Problemi Yekonomiki, 2(152), 230-238.

Burmatov: The Ministry of Education Is Hushing Up the Number of Graduates Who Failed the SUE (State Unified Exam). The official website of the "United Russia" party. Retrieved from http://er.ru/news/119798/

Chernykh, A. (n. d.). The SUE (State Unified Exam) to Be Sent Back for Retraining. Kommersant. Retrieved from http://www.kommersant.ru/doc/2527312

Coombs, P. H. (1985). The World Crisis Education: The View from the Eighties. New York, NY: Oxford University Press.

Fursenko: Remorenko Can Leave the Ministry of Education and Science Solely on His Own Initiative. RiaNovosti. Retrieved from http://ria.ru/politics/20130621/944958519.html

Gerasimov, A. N., Gromov, Y. I., \& Shatalova, O. I. (2013). Improvement of Methodological Support Forecasting of Key Indicators of Development of Regional Agro Production System. In the Proceedings of the 3rd International Research-to-Practice Conference "Science and Society" (Vol. 2, No. 20-21, pp. 232-242). London.

Gerasimov, A. N., Gromov, Y. I., Levchenko, O. P., Grigorieva, S. A., \& Oboturova, N. P. (2014). Features of the Spatial Socio-Economic Systems Development in the North Caucasus Federal District. World Applied Sciences Journal, 29(5), 699-705.

Gerasimov, A. N., Gromov, Y. I., Levchenko, S. A., Skrebtsova, T. V., \& Kobozev, M. A. (2013). The Modeling and Forecasting of Key Indicators of Socio-Economic Development of Traditionally Agrarian Regions. World Applied Sciences Journal, 27(10), 1282-1287.

Gorin, S. V., Sklyarov, I. Y., \& Kostyukova, Y. I. (2013). The Current State of Science Editing and Publishing in Russia. European Science Editing, 39(4), 87-89.

Kovalenko, A. (n. d.). Took It and Gave Up. Ekspert Ural. Retrieved from http:/expert.ru/ural/2014/29/sdalis/

Privalov, A. (n. d.). On a Kettlebell that Was Sawed Apart to the End At Last. Ekspert. Retrieved from http:/expert.ru/expert/2014/26/o-dopilennoj-nakonets-gire/

Privalov, A. (n. d.). On Galvanizing the Deceased SUE (State Unified Exam). Ekspert. Retrieved from http:/expert.ru/expert/2014/16/o-galvanizatsii-umershego-ege/

Saprankov, D. A. (n. d.). Specific Approaches towards Distinguishing Higher Professional Education and Boosting its Accessibility and Quality. Retrieved from http://www.scienceforum.ru/2013/pdf/4174.pdf

Shakhariyants, Y. V. (2010). The SUE (State Unified Exam) as a Form of Assessing Academic Achievements. Intellektualnyi Potentsial XXI Veka: Stupeni Poznaniya, 4(1), 106-112.

Sklyarov, I. Y., \& Sklyarova, Y. M. (2009). A Collective Success: The Effectiveness of Realizing a State Innovation Project. Kreativnaya Ekonomika, 6, 83-86.

Tatuev, A. A. (2012). Transformation of Priorities in Modernizing Higher Education in a Shift to a Knowledge Society. Ekonomicheskiy Analiz: Teoriya i Praktika, 8(263), 27-34.

Tatuev, A. A. (2013). Recessionary Trends in the Development of Russian Regions. In The Economy of the North Caucasus: Problems, Diagnosis, Prospects (Vol. 1). Logos Verlag Berlin.

Toffler, A. (2002). Power shift: Knowledge, Wealth and Violence at the Edge of the 21st Century. Moscow: AST.

Trukhachev, V. I. (2013). Creating a Healthy Future! Teoriya i Praktika Fizicheskoy Kultury, 9, 3-5.

Trukhachev, V. I., Kostyukova, Y. I., Gromov, Y. I., \& Gerasimov, A. N. (2014). A Comprehensive Socio-Ecological and Economic Assessment of the Status and Development of Southern Russia Agricultural Regions. Life Sci. J., 11(5), 478-482.

Zaitseva, I., \& Popova, M. (2013). A Technique to Study the Employment Potential of the Region: The Economic-Mathematical Aspect. World Applied Science Journal, 22(1), 22-25.

\section{Copyrights}

Copyright for this article is retained by the author(s), with first publication rights granted to the journal.

This is an open-access article distributed under the terms and conditions of the Creative Commons Attribution license (http://creativecommons.org/licenses/by/3.0/). 